\title{
EFEITO DA COENZIMA Q10 NOS DANOS OXIDATIVOS INDUZIDOS PELA L-TIROXINA NO MÚSCULO SÓLEO DE RATOS
}

\author{
EFFECT OF COENZYME Q10 IN THE L-THYROXINE-INDUCED OXIDATIVE DAMAGE \\ ON RAT SOLEUS MUSCLE \\ EFECTO DE LA COENZIMA Q1O EN LOS DAÑOS OXIDATIVOS INDUCIDOS POR LA L-TIROXINA
EN EL MÚSCULO SOLEO DE RATAS
}

Fabiana Barreiro de Freitas Silva (Fisioterapeuta)

Hyllana Catarine Dias de Medeiros (Zootecnista)

Marieli Guelfi' (Bióloga)

Andréia Tieme de Santana'

(Bióloga)

Fábio Erminio Mingatto

(Farmacêutico-Bioquímico)

\begin{abstract}
1. Universidade Estadual Paulista "Júlio de Mesquita Filho", Câmpus de Dracena, Dracena, SP. Brasil.
\end{abstract}

\section{Correspondência:}

Fábio Erminio Mingatto

Rod. Comandante João Ribeiro de Barros, km 651. 17900-000. Dracena, SP. Brasil.

fmingatto@dracena.unesp.br

\section{RESUMO}

Introdução: os músculoesqueléticos são tecidos dinâmicos que podem alterar suas características fenotípicas proporcionando melhor adaptação funcional com estímulos variados. A L-tiroxina é um hormônio produzido pela glândula tireoide e tem sido utilizada como modelo experimental para estimulação de estresse oxidativo no músculo esquelético. A coenzima Q10 é uma provitamina lipossolúvel sintetizada endogenamente e naturalmente encontrada em alimentos como carne vermelha, peixes, cereais, brócolis e espinafre. Apresenta propriedade antioxidante e tem potencial no tratamento de doenças degenerativas e neuromusculares. Objetivo: avaliar o efeito protetor da coenzima Q10 no músculo sóleo de ratos frente aos danos oxidativos provocados pela L-tiroxina. Métodos: os ratos foram distribuídos em quatro grupos de seis animais cada: Grupo 1 (controle); Grupo 2 (coenzima Q10); Grupo 3 (L-tiroxina) e Grupo 4 (coenzima Q10 e L-tiroxina). Após a eutanásia, o sangue dos animais foi colhido e foi analisada a atividade sérica das enzimas creatina quinase (CK) e aspartato aminotransferase (AST). No homogenato do músculo sóleo foram avaliados fatores relacionados ao estresse oxidativo. Resultados: a coenzima Q10 protegeu o músculo sóleo dos danos provocados pela L-tiroxina e favoreceu a manutenção da atividade das enzimas antioxidantes glutationa redutase e glutationa peroxidase, da concentração de glutationa reduzida e oxidada, além de evitar a lipoperoxidação. Conclusão: os resultados indicam que a coenzima Q10 protege o músculo sóleo de ratos dos danos oxidativos provocados pela L-tiroxina.

Palavras-chave: radicais livres, antioxidantes, suplementação alimentar.

\section{ABSTRACT}

Introduction: skeletal muscles are dynamic tissue that can change their phenotypic characteristics providing a better functional adaptation to different stimuli. L-thyroxine is a hormone produced by the thyroid gland and has been used as an experimental model for stimulation of oxidative stress in skeletal muscle. Coenzyme Q10 (CoQ10) is a fat-soluble provitamin endogenously synthesized and found naturally in foods such red meat, fish, cereals, broccoli and spinach. It has antioxidant properties and potential in the treatment of degenerative and neuromuscular diseases. Objective: to evaluate the protective effect of $\mathrm{COQ} 10$ in the soleus muscle of rats against the oxidative damage caused by L-thyroxine. Methods: the rats were divided in four groups of six animals each: Group 1 (control); Group 2 (coenzyme Q10); Group 3 ( L-thyroxine), and Group 4 coenzyme Q10 and L-thyroxine). After euthanasia, blood was collected and serum activity of theenzymes creatine kinase (CK) and aspartate aminotransferase (AST) was analyzed. In the soleus muscle homogenates the factors related to oxidative stress were assessed. Results: $\mathrm{COQ} 10$ protected the soleus muscle against the damage caused by L-thyroxine and favored the maintenance of the antioxidant enzymes glutathione reductase and glutathione peroxidase, the concentration of decreased and oxidized glutathione, and prevented lipid peroxidation. Conclusion: the results indicate that CoQ10 protects rat soleus muscle from oxidative damage caused by L-thyroxine.

Keywords: free radicals, antioxidants, supplementary feeding.

\section{RESUMEN}

Introducción: los músculos esqueléticos son tejidos dinámicos que pueden alterar sus características fenotípicas proporcionando mejor adaptación funcional con estímulos variados. La L-tiroxina es una hormona producida por la glándula tiroides y ha sido utilizada como modelo experimental para estimulación de estrés oxidativo en el músculo esquelético. La coenzima Q10 es una provitamina liposoluble sintetizada endogénicamente y naturalmente encontrada en alimentos como carne roja, pescados, cereales, brócolis y espinaca. Presenta propiedad antioxidante y tiene potencial en el tratamiento de enfermedades degenerativas y neuromusculares. Objetivo: evaluar el efecto protector de la coenzima Q10 en el músculo soleo de ratas frente a los daños oxidativos provocados por la L-tiroxina. Métodos: Las ratas fueron distribuidas en cuatro grupos de seis animales cada uno: Grupo 1 (control); Grupo 2 (coenzima Q10); Grupo 3 (L-tiroxina) y Grupo 4 (coenzima Q10 y L-tiroxina). Después de la eutanasia, la sangre de los animales fue recogida y fue analizada la actividad sérica de las enzimas creatina quinasa (CK) y aspartato aminotransferasa 
(AST). En el homogenato del músculo soleo fueron evaluados factores relacionados al estrés oxidativo. Resultados: la coenzima Q10 protegió al músculo soleo de los daños provocados por la L-tiroxina y favoreció el mantenimiento de la actividad de las enzimas antioxidantes glutationa reductasa y glutationa peroxidasa, de la concentración de glutationa reducida y oxidada, además de evitar la lipoperoxidación. Conclusión: Ios resultados indican que la coenzima Q10 protege al músculo soleo de ratas de los daños oxidativos provocados por la L-tiroxina.

Palabras clave: radicales libres, antioxidantes, alimentación suplementaria.

\section{INTRODUÇÃO}

Os musculoesqueléticos adultos são compostos de vários tipos de fibras, sendo caracterizados por diferenças quanto ao tipo de contração e classificados em dois grandes grupos, lento ou de contração lenta (tipo I) e rápido ou de contração rápida (tipo II) ${ }^{1}$. Músculos posturais como, por exemplo, o sóleo, possuem maior proporção de fibras tipo I, oxidativas e resistentes à fadiga, enquanto os músculos envolvidos em atividades rápidas e que exigem força, como por exemplo, o bíceps braquial, possuem maior quantidade de fibras tipo II, altamente fadigáveis².

Espécies reativas de oxigênio (ERO) são formadas durante o metabolismo normal, por processos enzimáticos e não enzimáticos, e continuamente, causam danos oxidativos a lipídios, proteínas e ácidos nucléicos celulares ${ }^{3,4}$. Para se protegerem contra a oxidação, os organismos contam com mecanismos químicos e enzimáticos 5 . O exercício físico é uma condição que exerce influência sobre o balanço entre ataque oxidativo e mecanismo de defesa antioxidante, condição conhecida como estresse oxidativo, uma vez que durante o exercício físico ocorrem várias reações químicas que implicam na formação de $\mathrm{ERO}^{6}$.

A tiroxina (T4) é um hormônio produzido pela glândula tireoide que age no fígado, rim, coração, sistema nervoso e no músculo esquelético, sensibilizando esses tecidos à adrenalina e estimulando o metabolismo celular e o consumo de oxigênio. A aceleração do metabolismo estimulada pela tiroxina provoca aumento na produção de calor. O que é de suma importância na termorregulação de muitos vertebrados ${ }^{7}$. A elevação do metabolismo basal e do consumo de oxigênio ocasionada pela alta produção de tiroxina, conhecida como hipertireoidismo, predispõe a célula a produzir espécies reativas de oxigênio ${ }^{8}$, podendo ser utilizada como modelo experimental para estimulação de estresse oxidativo no musculoesquelético 9,10

O exercício físico induz aumento de até 20 vezes no volume de oxigênio total consumido $\left(\mathrm{VO}_{2}\right)^{11}$. Assumindo que cerca de 2 a $5 \%$ do $\mathrm{O}_{2}$ consumido dá origem a espécies reativas de oxigênio (ERO), esse aumento no consumo de oxigênio induzido pelo exercício físico está associado ao aumento na produção de tais espécies ${ }^{12}$. A alta produção de ERO é responsável por várias ações deletérias, tais como aumento nos níveis de peroxidação de lipídios de membranas ${ }^{13}$, aumento na carbonilação de proteínas e até danos ao DNA intracelular ${ }^{14}$, o que em última instância altera e prejudica o metabolismo intracelular.

A coenzima Q10 (CoQ10) possui várias funções bioquímicas nas células $^{15}$, sendo a principal aquela exercida pela sua forma quinona, a qual transfere elétrons na cadeia de transporte de elétrons mitocondrial dos complexos I e II para o complexo III, processo durante o qual prótons são bombeados para o espaço intermembranar gerando assim um gradiente eletroquímico transmembrana usado na fosforilação oxidativa ${ }^{16}$. A forma quinol da CoQ10 age como um potente antioxidante na membrana mitocondrial interna. Ela inibe a lipoperoxidação, ou por apresentar um efeito sequestrante de radicais livres, ou reduzindo o radical $\alpha$-tocoferoxil a $\alpha$-tocoferol ${ }^{17,18}$. A CoQ10 tem sido utilizada como suplemento dietético e em conjunto com medicamentos em várias situações, incluindo doenças cardiovasculares, câncer, doenças neuromusculares degenerativas e diabetes ${ }^{19-21}$. Portanto, neste trabaIho foi avaliado o efeito protetor da coenzima Q10 sobre o estresse oxidativo provocado no músculo sóleo de ratos pela L-tiroxina e os mecanismos envolvidos.

\section{MATERIAL E MÉTODOS}

A L-tiroxina e a coenzima Q10 100\% puros foram adquiridas da empresa Pharma Nostra Ltda (Rio de Janeiro, Brasil).

Ratos Wistar machos de aproximadamente $200 \mathrm{~g}$, provenientes do Biotério Central da Unesp (Campus de Botucatu), ficaram alojados no Biotério do Campus de Dracena, em número de 6 animais por caixa, com cobertura metálica e serragem de madeira. As caixas plásticas, com dimensões (CxLXA) 41×34x16 cm, foram armazenadas sob temperatura controlada de aproximadamente $22^{\circ} \mathrm{C}$. Os animais receberam alimento e água ad libitum e foram divididos em quatro grupos de seis animais de acordo com cada tratamento, por 30 dias: Grupo 1 (G1, controle), recebeu apenas o veículo da L-tiroxina e óleo de milho (via intraperitoneal); Grupo 2 (G2), recebeu o veículo da L-tiroxina e coenzima Q10 $\left(10 \mathrm{mg} / \mathrm{kg}\right.$ de peso vivo, de acordo com El-Sheikh et al. $^{21}$ ) dissolvida em óleo de milho (via oral por gavagem); Grupo 3 (G3), recebeu a L-tiroxina $\left(0,3 \mathrm{mg} / \mathrm{kg}\right.$ de peso vivo $\left.{ }^{22}\right)$ dissolvida em $\mathrm{NaOH}$ 0,01 M, e posteriormente diluída 10 vezes em soro fisiológico estéril; Grupo 4 (G4), recebeu a coenzima Q10 (via oral) e L-tiroxina (via intraperitoneal).

A Comissão de Ética em Uso de Animais (CEUA) do Campus da Unesp de Dracena, Brasil, certificou que os procedimentos utilizando animais estão de acordo com os "Princípios Éticos na Experimentação Animal" (Protocolo n. 35/2012).

Os parâmetros bioquímicos: atividade das enzimas creatina quinase (CK) e aspartato aminotransferase (AST) no soro sanguíneo, e a atividade das enzimas glutationa redutase (GR) e glutationa peroxidase (GPx), concentração de glutationa reduzida (GSH) e oxidada (GSSG), e lipoperoxidação no homogenato do músculo sóleo de rato foram avaliados.

O sangue dos animais foi colhido individualmente em tubos tipo "Falcon" de 15 mL e mantidos à temperatura ambiente por 15 minutos para coagulação. O soro foi separado por centrifugação, com velocidade de 3000 rpm por 15 minutos mantidos em gelo a 4․ A atividade sérica das enzimas indicadoras de lesões musculares (AST e CK) foi dosada por meio de kits comerciais (Bioclin, Belo Horizonte, Brasil) de acordo com as instruções do fabricante.

Após a eutanásia, o músculo sóleo dos animais foi retirado e colocado em um béquer com 1,0 mL de meio contendo sacarose 250 mM, EGTA $1 \mathrm{mM}$ e HEPES $10 \mathrm{mM} \mathrm{com} \mathrm{pH} \mathrm{7,2} \mathrm{a} 4^{\circ} \mathrm{C}$, onde foi cortado com tesoura e transferido para um tubo de ensaio com o uso de mais 1,0 mL do meio. O músculo picotado foi levado para um homogeneizador do tipo turrax e homogeneizado 3 vezes por 15 s com intervalos de 1 minuto.

A determinação de proteína no homogenato do meio foi realizada pela reação do biureto, de acordo com Cain e Skilleter ${ }^{23}$ usando-se albumina de soro bovino (BSA) como padrão.

A atividade da enzima GPx foi determinada de acordo com o método de Hafeman et al. ${ }^{24}$ com algumas modificações. Em cubeta 
de quartzo de volume de $4 \mathrm{~mL}$ foram adicionados, $1 \mathrm{~mL}$ de tampão fosfato de sódio 0,1 mM, pH 7,6, contendo EDTA 0,5 mM, $10 \mu \mathrm{L}$ de triton X-100 a 10\%, homogenato do músculo sóleo (1 mg de proteína), $5 \mu \mathrm{L}$ de GSH 100 mM e $20 \mu \mathrm{L}$ de NADPH 10 mM. Após 1 minuto de incubação, foram adicionados $10 \mu \mathrm{L}$ de $\mathrm{H}_{2} \mathrm{O}_{2} 25 \mathrm{mM}$ e a variação da absorbância foi determinada no comprimento de onda de $340 \mathrm{~nm}$ em um espectrofotômetro Beckman-Coulter modelo DU-800 (Fullerton, CA, USA). Os dados foram expressos em U/mg de proteína.

$A$ atividade da enzima GR foi determinada de acordo com o método de Carlberg e Mannervick ${ }^{25}$ com algumas modificações. Em cubeta de quartzo de volume de $4 \mathrm{~mL}$ foram adicionados, $1 \mathrm{~mL}$ de tampão fosfato de sódio 0,1 mM, pH 7,6, contendo EDTA 0,5 mM, $10 \mu \mathrm{L}$ de triton X-100 a 10\%, homogenato do músculo sóleo (1 mg de proteína) e $10 \mu \mathrm{L}$ de GSSG $100 \mathrm{mM}$. Em seguida as amostras foram incubadas a $30^{\circ} \mathrm{C}$ por 5 minutos. Logo após foram adicionados $10 \mu \mathrm{L}$ de NADPH $10 \mathrm{mM}$ e a variação da absorbância foi determinada no comprimento de onda de 340 nm em um espectrofotômetro Beckman-Coulter modelo DU-800 (Fullerton, CA, USA). Os dados foram expressos em U/mg de proteína.

A determinação da concentração de GSH e GSSG no homogenato de músculo sóleo dos animais foi realizada de acordo com Hissin e Hilf (1976). Em tubos do tipo "eppendorf" de $2 \mathrm{~mL}$, foram adicionados o homogenato (1 mg de proteína), meio contendo sacarose 125 mM, KCl 65 mM e HEPES-KOH 10 mM, pH 7,4 para completar $1 \mathrm{~mL}$ e após uma leve homegeneização foram adicionados $500 \mu \mathrm{L}$ de ácido tricloroacético 13\%. A mistura foi agitada e centrifugada a $9000 \mathrm{~g}$ por 3 min. Para a dosagem de GSH, em tubos de ensaio de $5 \mathrm{~mL}$ foram adicionados $1800 \mu \mathrm{L}$ de tampão contendo $\mathrm{NaH}_{2} \mathrm{PO}_{4} 0,1 \mathrm{M}, \mathrm{pH}$ 8,0, com EDTA $5 \mathrm{mM}, 100 \mu \mathrm{L}$ do sobrenadante obtido da centrifugação e $100 \mu \mathrm{L}$ de OPT (o-ftalaldeído) $1 \mathrm{mg} / \mathrm{mL}$. Em seguida os tubos foram agitados e mantidos por 15 minutos no escuro à temperatura ambiente. Foi efetuada a leitura em espectrofluorímetro RFPC 5301 (Shimadzu, Japão) com comprimento de onda de 350 e 420 nm para emissão e excitação, respectivamente, com abertura de fenda três em ambos os casos.

Para a dosagem de GSSG, $250 \mu \mathrm{L}$ do sobrenadante inicial foram tratados com $250 \mu \mathrm{L}$ de N-etilmaleimida (NEM) 0,04 M e submetidos ao mesmo procedimento de mistura com o OPT descrito anteriormente. As concentrações de GSH e GSSG foram estimadas por meio de uma curva padrão.

A peroxidação de lipídios de membrana foi determinada utilizando o método do TBARS (substâncias reativas ao ácido tiobarbitúrico) de acordo com Ohkawa et al. ${ }^{26}$. Para tanto, o homogenato do músculo sóleo (5 mg de proteína) foi colocado em tubo de ensaio e foram adicionados 0,2 mL de SDS (8,1\%), 1,5 mL de ácido acético (20\%), 1,5 mL de TBA (solução aquosa a 0,67\%), o volume foi completado até $4 \mathrm{~mL}$ com água deionizada (milli-Q) e a mistura colocada em banho-maria a $95^{\circ} \mathrm{C}$ por 60 min. Após o período de incubação os tubos foram retirados e resfriados em banho de gelo e adicionado $1 \mathrm{~mL}$ de água milli-Q e o complexo MDA-TBA extraído com $5 \mathrm{~mL}$ de $\mathrm{n}$-butanol. Em seguida os tubos foram centrifugados a $2000 \mathrm{~g}$ por 10 minutos, a parte orgânica foi coletada e a absorbância medida a $535 \mathrm{~nm}$. A concentração de malondialdeído (MDA) foi determinada utilizando-se o coeficiente de extinção molar de $1,56 \times 10^{5} \mathrm{M}^{-1} \mathrm{~cm}^{-1}$. Os dados foram expressos em nmol/mg de proteína.

\section{Análise estatística}

A normalidade dos dados foi avaliada pelo teste de Kolmogorov-Smirnov. A significância estatística dos dados experimentais foi determinada pelo teste de análise de variância (ANOVA), seguido do teste de comparações múltiplas de Tukey, sendo considerados estatisticamente significantes resultados com valores de $P<0,05$. As análises foram realizadas aplicando o programa GraphPad Prism, versão 4.0 para Windows, GraphPad Software (San Diego, CA, USA 03/04/2003).

\section{RESULTADOS}

O tratamento com L-tiroxina (G3) promoveu aumento significativo na atividade sérica das enzimas CK e AST (figuras 1A e 1B, respectivamente) em relação ao controle (G1), as quais foram utilizadas como parâmetro de lesão muscular. A comparação entre os grupos 3 e 4 mostra que o tratamento com a coenzima Q10 protegeu o músculo sóleo dos danos provocados pela L-tiroxina conforme observado pela diminuição significativa da liberação das enzimas (G4).

A análise da atividade das enzimas GPx e GR no homogenato de músculo sóleo (figuras $2 \mathrm{~A}$ e $2 \mathrm{~B}$, respectivamente) demonstrou que houve uma redução significativa no grupo tratado com a L-tiroxina (G3) em relação ao controle (G1). O tratamento dos animais com a coenzima Q10 protegeu contra o efeito provocado pela L-tiroxina sobre as enzimas (G4).

O tratamento dos animais com a L-tiroxina (G3) promoveu redução significativa na concentração de GSH no homogenato de músculo sóleo em relação ao grupo controle (figura $3 \mathrm{~A}$ ). $\mathrm{O}$ tratamento dos animais com a coenzima Q10 protegeu o músculo contra o efeito da L-tiroxina (G4). Ao mesmo tempo, observou-se aumento na concentração de GSSG no homogenato de músculo sóleo dos animais tratados com L-tiroxina (G3) indicando que essa substância induziu a oxidação da glutationa presente no músculo (figura 3B). O tratamento dos animais com a coenzima Q10 também protegeu o músculo contra o efeito da L-tiroxina (G4).

A oxidação dos lipídios de membrana do homogenato de músculo sóleo foi avaliada por meio da produção do malondialdeído (MDA). Em relação à concentração de MDA, os resultados demonstram que o tratamento com L-tiroxina (G3) estimulou significativamente o aumento na produção desse composto em relação ao grupo controle (G1), indicando que houve peroxidação dos lipídios de membrana (figura 4). O tratamento com a coenzima Q10 protegeu o músculo contra os danos oxidativos provocados pela L-tiroxina (G4).

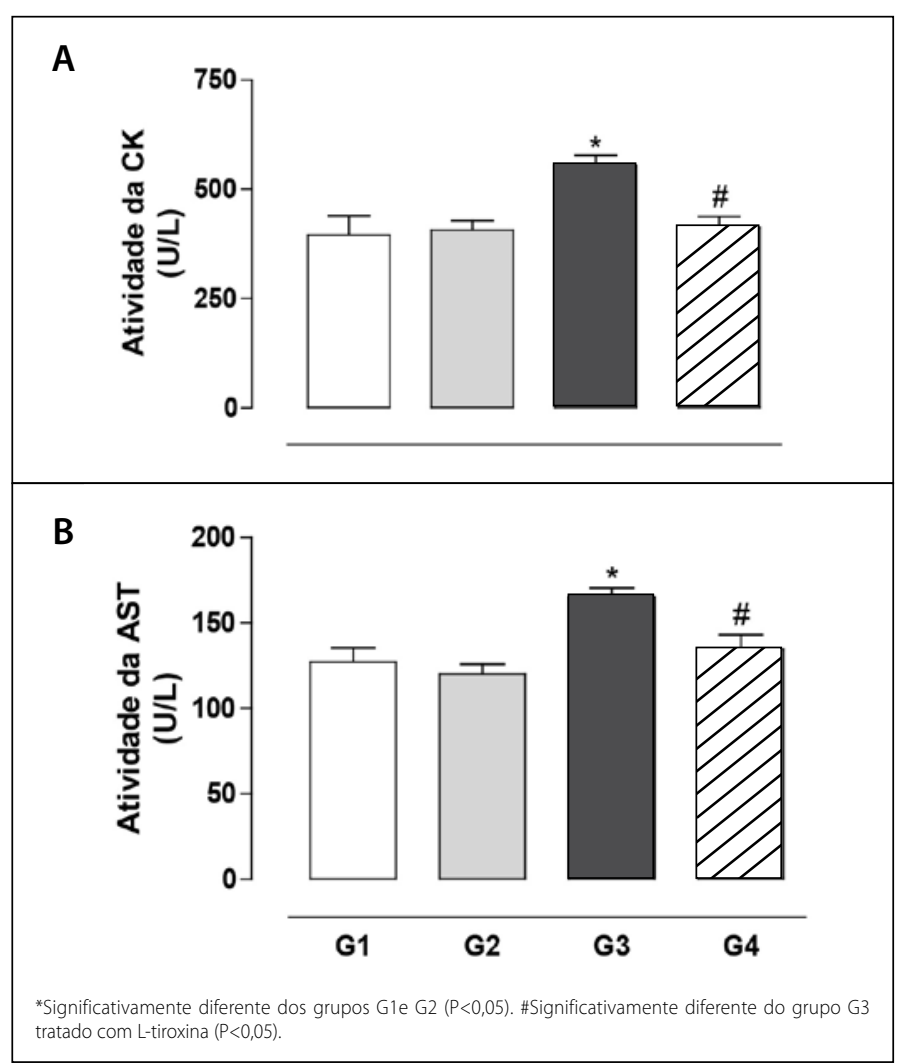

Figura 1. Atividade das enzimas creatina quinase (CK) e aspartato aminotransferase (AST) no soro de ratos. Os resultados representam a média \pm EPM de 6 animais por grupo. G1 = controle; G2 = controle CoQ10; G3 = L-tiroxina; G4 = L-tiroxina + CoQ10. 


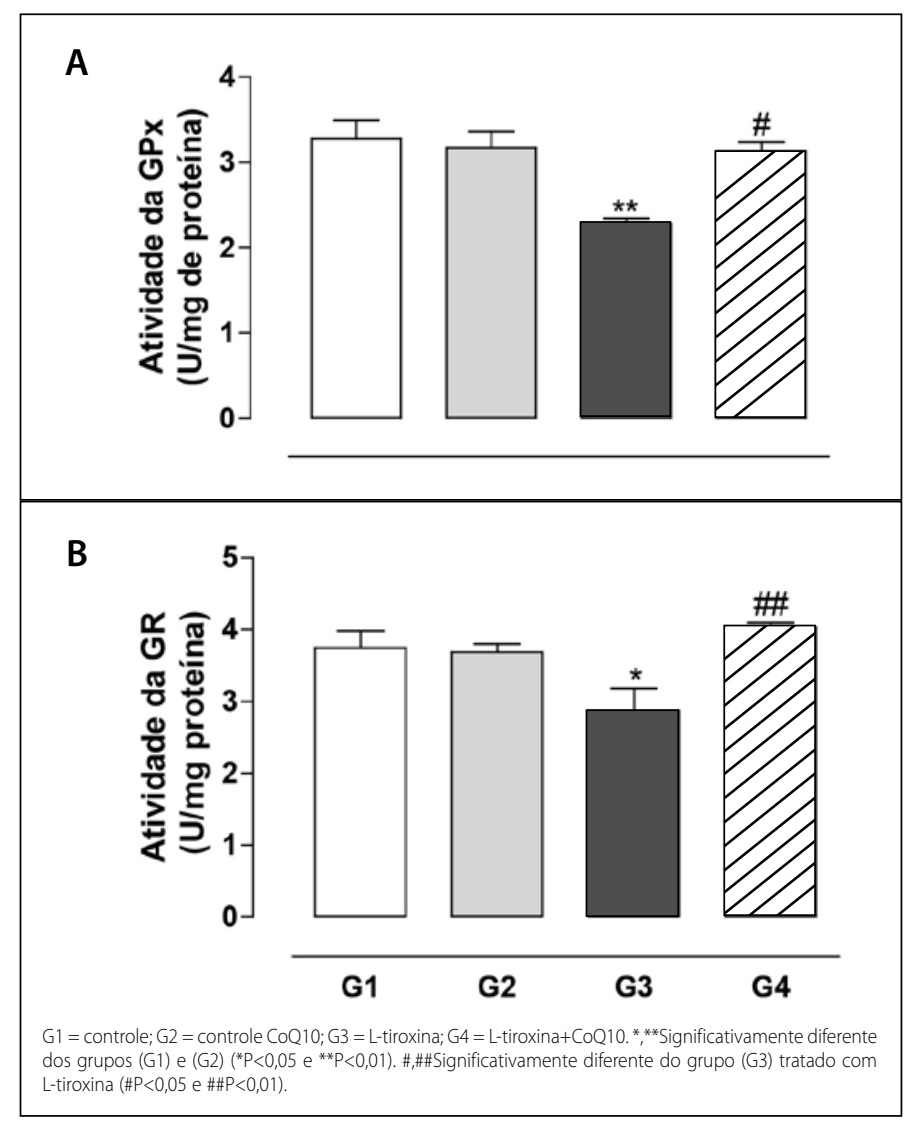

Figura 2. Efeito protetor da coenzima Q10 (CoQ10) sobre a diminuição da atividade da enzimas glutationa peroxidase (GPX) e glutationa redutase (GR) induzida pela L-tiroxina no homogenato de músculo sóleo de ratos. Os resultados representam a média \pm EPM de 6 animais por grupo.

A

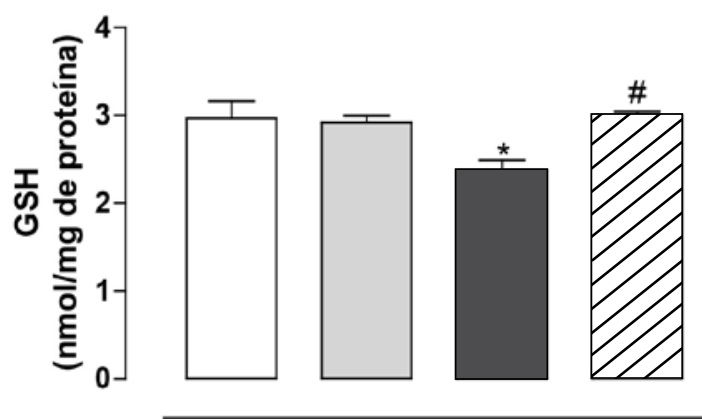

B

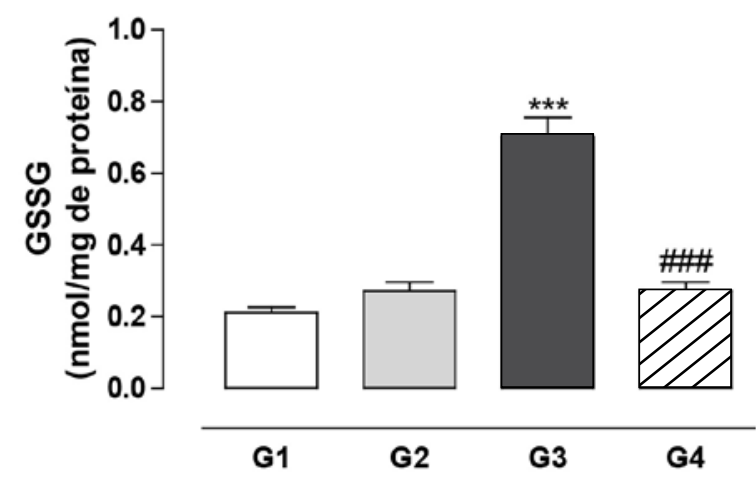

$\mathrm{G} 1$ = controle; $\mathrm{G} 2$ = controle CoQ10; $\mathrm{G} 3$ = L-tiroxina; G4 = L-tiroxina+CoQ10. ${ }^{* * * *}$ Significativamente diferente dos grupos (G1) e (G2) $\left.{ }^{*} \mathrm{P}<0,05 \mathrm{e}^{* * *} \mathrm{P}<0,001\right)$. \#,\#\#\#Significativamente diferente do tratado com L-tiroxina (G3) (\#P $<0,05$ e \#\#\# $<0,001)$.

Figura 3. Efeito da coenzima Q10 sobre a variação na concentração de GSH e GSSG induzida pela L-tiroxina no homogenato de músculo sóleo de ratos. Os resultados representam a média \pm EPM de seis animais por grupo.

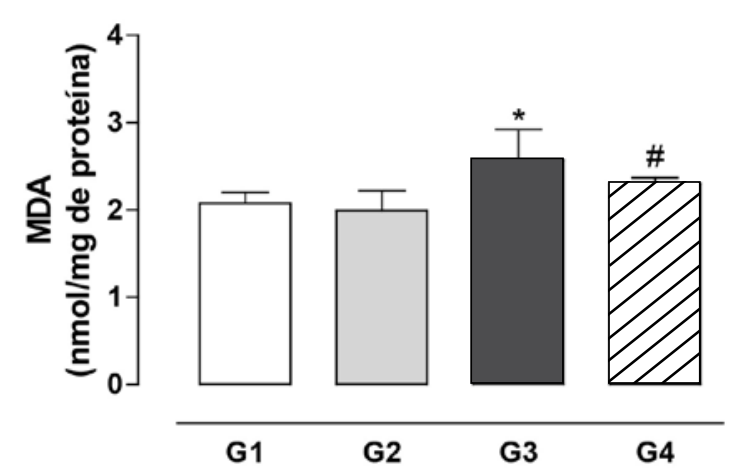

$\mathrm{G} 1=$ controle; $\mathrm{G} 2$ = controle CoQ10; G3 = L-tiroxina; G4 = L-tiroxina + CoQ10. *Significativamente diferente dos grupos $(G 1)$ e $(G 2)(P<0,05)$. \#Significativamente diferente do tratado com L-tiroxina $(G 3)(P<0,05)$.

Figura 4. Efeito protetor da coenzima Q10 (CoQ10) sobre o aumento na concentração de MDA induzido pela L-tiroxina no homogenato de músculo sóleo de ratos. Os resultados representam a média \pm EPM de 6 animais por grupo.

\section{DISCUSSÃO}

Estudos recentes demonstraram a importância da CoQ10 na resistência do DNA aos danos oxidativos. O interesse pela CoQ10 tem aumentado nos últimos anos, principalmente devido a capacidade de transferir elétrons e atuar como antioxidante ${ }^{19}$. Na sua forma reduzida, a CoQ10 é um poderoso antioxidante que previne os danos oxidativos causados pelos radicais livres, incluindo a oxidação de lipídios na membrana mitocondrial. Sua atuação como antioxidante também ocorre por meio da ativação e aumento da expressão de proteínas mitocondriais desacopladoras, um efeito antiapoptótico que resulta na redução de geração de radicais livres ${ }^{27,28}$.

O exercício induz mudanças reversíveis na ultraestrutura do músculo esquelético, com elevação da permeabilidade do sarcolema e das proteínas musculares, tais como a mioglobina, creatina quinase (CK) e a aspartato aminiotransferase (AST) que são liberadas na circulação 29 . Sendo assim, a determinação da atividade sérica das duas enzimas, CK e AST, fornece uma clara indicação de uma provável lesão tecidual ${ }^{30}$.

Neste estudo, no grupo tratado com a L-tiroxina os valores de AST e CK estão significativamente aumentados, comprovando que a substância pode ser usada para simular os danos musculares resultantes do exercício, e fazendo uma comparação com os grupos tratados com e sem a CoQ10, foi possível observar o efeito protetor da mesma contra os danos musculares provocados pela L-tiroxina.

Segundo Bentinger et al..$^{31}$ a coenzima Q10 tem como função primária prevenir a produção de radicais livres e a iniciação do processo de peroxidação lipídica.

Fisiologicamente, o organismo pode se defender da agressão mediada pelas espécies reativas de oxigênio (ERO) utilizando-se das reservas de enzimas antioxidantes, entre elas a glutationa peroxidase (GPx) e a glutationa redutase $(\mathrm{GR})^{3}$. Os resultados deste estudo mostraram uma diminuição na atividade das enzimas GPx e GR conforme observado no homogenato de músculo sóleo dos animais tratados com L-tiroxina em comparação com o grupo controle. Esses dados estão de acordo com Seymen et al. ${ }^{10}$ que relataram que o tratamento com a L-tiroxina induz a formação de $E R O$ e provoca consequentemente uma inibição da atividade específica da GPx, enzima responsável pela conversão de $\mathrm{H}_{2} \mathrm{O}_{2}$ em $\mathrm{H}_{2} \mathrm{O}$. O tratamento dos animais com a CoQ10, demonstrou efeito protetor da substância, uma vez que a atividade das enzimas GPx e GR foram reestabelecidas para valores próximos ao grupo controle.

A glutationa reduzida (GSH) pode ser considerada um dos agentes mais importantes do sistema de defesa antioxidante da célula, protegendo-a contra a lesão resultante da exposição a agentes oxidantes ${ }^{32}$. 
O estresse oxidativo é caracterizado por diminuição na concentração de GSH, aumentos na glutationa oxidada (GSSG) e lipoperoxidação, bem como redução da atividade de enzimas antioxidante ${ }^{33}$. O tratamento com a L-tiroxina induziu o estresse oxidativo no homogenato do músculo sóleo de ratos como indicado pela diminuição nas concentrações de GSH e um aumento nas concentrações de GSSG no homogenato analisado. Essas alterações encontradas no ciclo redox da glutationa no presente estudo condizem com os encontrados por Seymen et al. ${ }^{10}$ no músculo esquelético e Mohamadin et al. ${ }^{22}$ no músculo cardíaco de ratos, os quais demonstraram diminuição significativa da GSH e aumento da GSSG em animais tratados com L-tiroxina. Em nosso estudo, o tratamento dos animais com a CoQ10, reestabeleceu as concentrações de GSH e GSSG, indicando efeito antioxidante da substância.

De acordo com Seymen et al. ${ }^{10}$ a L-tiroxina estimula a geração de peróxidos lipídicos, e estes por sua vez promovem danos à membrana plasmática. Estes efeitos são condizentes aos apresentados neste estudo, visto que pela análise do homogenato constatou-se que ocorreu elevação na formação do MDA no homogenato de músculo sóleo dos animais tratados com a L-tiroxina, indicando a ocorrência da peroxidação lipídica. Resultado semelhante foi relatado por Sahoo et al. ${ }^{34}$, quando avaliaram os efeitos da L-tiroxina sobre o testículo de ratos.
No presente estudo, o tratamento com a CoQ10 protegeu o músculo sóleo contra este efeito oxidante, o que pode estar associado ao fato da CoQ10 atuar como antioxidante protegendo os lipídios de membrana contra o efeito oxidativo provocado pelos radicais livre ${ }^{21,35,36}$.

Nossos resultados indicam que a CoQ10 protege o músculo de ratos de danos oxidativos provocados pela L-tiroxina uma vez que ela manteve a atividade das enzimas glutationa redutase e glutationa peroxidade e diminuiu a lipoperoxidação. Essa proteção pode estar principalmente relacionada com a atividade antioxidante da CoQ10 e seu uso terapêutico pode ser considerado em situações clínicas.

\section{CONCLUSÃO}

De acordo com os dados obtidos neste estudo pode se concluir que a CoQ10 é capaz de impedir os danos oxidativos provocados pela L-tiroxina no músculo sóleo. Dessa forma, pode-se sugerir o uso da CoQ10 para a suplementação de atletas sujeitos a danos oxidativos provocados pelo exercício.

Todos os autores declararam não haver qualquer potencial conflito de interesses referente a este artigo.

\section{REFERÊNCIAS}

1. Lefreuve B, Crossim F, Fontaine-Perus J, Bandmam E, Gardahuat MF. Innervation regulates myosin heavy chain isoform expression in developing skeletal muscle fibers. Mech Dev. 1996;58(1-2):115-27.

2. Goldspink G. Mechanical signals, IGF-I gene splicing, and muscle adaptation. Physiology (Bethesda). 2005;20:232-8.

3. Halliwell B, Gutteridge JMC. Free radicals in biology and medicine. 4th edition. Oxford: Clarendon; 2007.

4. Gutteridge JMC. Lipid peroxidation and antioxidants as biomarkers of tissue damage. Clinic Chemist. 1995;41(12):1819-28.

5. Yu BP. Cellular defenses against damage from reactive oxygen species. Physiol Rev. 1994;74(1):139-62.

6. Sen CK. Antioxidants in exercise nutrition. Sports Med. 2001;31(13):891-908.

7. Aires MM. Fisiologia. 3a. ed. Rio de Janeiro: Guanabara; 2008.

8. Asayama K, Dobashi K, Hayashibe H, Megata Y, Kato K. Lipid peroxidation and free radical scavengers in thyroid disfunction in the rat: a possible mechanism on injury to heart and skeletal muscle in hyperthyroidism. Endocrinology. 1987;121(6):2112-18.

9. Asayama K, Dobashi K, Hayashibe H, Kato K. Vitamin E protects against thyroxine-induced acceleration of lipid peroxidation in cardiac and skeletal muscles in rats. J Nutr Sci Vitaminol. 1989;35(5):407-18.

10. Seymen HO, Civelek S, Seven, Yig it G, Hatemi H, Burçak G. Iron supplementation in experimental hyperthyroidism: effects on oxidative stress in skeletal muscle tissue. Yonsei Med J. 2004;45(3):413-18.

11. Astrand PO, Rodahl K, Dahl H, Stromme SB. Textbook of work physiology. 4th edition. Champaign: Human Kinetics Publishers; 2003.

12. Jenkins RR, Goldfarb A. Introduction: oxidant stress, aging and exercise. Med Sci Sports Exerc. 1993;25(2):210-12.

13. Alessio HM. Exercise-induce oxidative stress. Med Sci Sports Exerc. 1993;25(2):218-24.

14. Jansen KM1, Pavlath GK. Mannose receptor regulates myoblast motility and muscle growth. J Cell Biol. 2006;174(3):403-13

15. Crane FL. Biochemical functions of coenzyme Q10. J Am Coll Nutr. 2001;20(6):591-8.

16. Ernster L, Dallner G. Biochemical, physiological and medical aspects of ubiquinone function. Biochim Biophys Acta. 1995;1271(1):195-204.

17. Kagan V, Serbinova E, Packer L. Antioxidant effects of ubiquinones in microssomes and mitochondria are mediated by tocopherol recycling. Biochem Biophys Res Commun. 1990;169(3):851-57.

18. Lass A, Sohal RS. Electron transport-linked ubiquinone dependent recycling of $\alpha$-tocopherol inhibits autoxidation of mitochondrial membranes. Arch Biochem Biophys. 1998;352(2):229-36.

19. Kumar A, Kaur H, Devi P, Mohan V. Role of coenzyme Q10 (CoQ10) in cardiac disease, hypertension and Meniere-like syndrome. Pharmacol Ther. 2009;124(3):259-68.
20. Villalba JM, Parrado C, Santos-Gonzalez M, Alcain FJ. Therapeutic use of coenzyme Q10 and coenzyme Q10-related compounds and formulations. Expert Opin Investig Drugs. 2010;19(4):535-54.

21. El-Sheikh AAK, Morsy MA, Mahmoud MM, Rifaai RA, Abdelrahman AM. Effect of coenzyme-Q10 on doxorubicin-Induced nephrotoxicity in rats. Adv Phar Sci. 2012;2012:981461.

22. Mohamadin AM, Hammad LN, El-Bab MF, Abdel Gawad HS. Attenuation of oxidative stress in plasma and tissues of rats with experimentally induced hyperthyroidism by caffeic acid phenylethyl. Basic Clin Pharmacol Toxicol. 2007;100(2):84-90

23. Cain K, Skilleter DN. Preparation and use of mitochondria in toxicological research. In: Snell K, Mullock B, editors. Biochemical toxicology. Oxford: IRL Press; 1987. p. 217-54.

24. Hafemann DG, Sunde RA, Hoekstra WG. Effect of dietary selenium on erythrocyte and liver glutathione peroxidase in the rat. J Nutr. 1974;104(5):580-7.

25. Carlberg I, Mannervik B. Purification and characterization of the flavoenzyme glutathione reductase from rat liver. J Biol Chem. 1975;250(14):5475-80.

26. Ohkawa H, Ohishi N, Yagi K. Assay for lipid peroxides in animal tissues by thiobarbituric acid reaction. Anal Biochem. 1979;95(2):351-58.

27. Chaturvedi RK, Beal MF. Mitochondrial approaches for neuroprotection. Ann N Y Acad Sci. 2008;1147:395-412.

28. Marcoff L, Thompson PD. The role of coenzyme Q10 in statin-associated myopathy: a systematic review. J Am Coll Cardiol. 2007;49(23):2231-37.

29. McCurtchen $\sqcup$, Byrd SK, Hodgson DR. Ultrastructural changes in skeletal muscle after fatiguing exercise. J Appl Physiol. 1992;72(3):1111-7.

30. Motta VT. Bioquímica clínica: princípios e interpretações. Porto Alegre: Missau; 2003.

31. Bentinger M, Brismar K, Dallner G. The antioxidant role of coenzyme Q. Mitochondrion. 2007;7(Suppl 7):41-50.

32. Jordão Junior AA, Chiarello PG, Bernardes MSM, Vannucchi H. Peroxidação lipídica e etanol: papel da glutationa reduzida e da vitamina E. Medicina (Ribeirão Preto). 1998;31:434-49.

33. Sies H. Biochemistry of oxidative stress. Angew Chem Int Ed. 1986;25:1058-71.

34. Sahoo DK, Roy A, Chainy GBN. Protective effects of vitamin E and curcumin on L-thyroxine-induced rat testicular oxidative stress. Chem-Biol Interact. 2008;176 (2-3):121-8.

35. Alleva R, Tomasetti M, Battino M, Curatola G, Littarru GP, Folkers K. The roles of coenzyme Q10 and vitamin $\mathrm{E}$ on the peroxidation of human low density lipoprotein subfractions. Proc Natl Acad Sci USA. 1995;92(20):9388-91.

36. Singh U, Devaraj S, Jialal I. Coenzyme Q10 supplementation and heart failure. Nutr Rev. 2007;65(6):286-93. 